\title{
Endobronchial valve therapy for a refractory air leak after lung transplantation in a patient with multiple connective tissue disorders
}

John R. Spratt, MD, Eitan Podgaetz, MD, Gabriel Loor, MD, and Sara J. Shumway, MD, Minneapolis, Minn

\footnotetext{
From the Department of Surgery, University of Minnesota Medical School, Minneapolis, Minn.

Disclosures: Authors have nothing to disclose with regard to commercial support.

Received for publication June 14, 2016; revisions received Sept 23, 2016; accepted for publication Sept 30, 2016; available ahead of print Nov 1, 2016

Address for reprints: Sara J. Shumway, MD, Division of Cardiothoracic Surgery, Department of Surgery, University of Minnesota Medical School, 420 Delaware St SE, Mayo Mail Code 195, Minneapolis, MN 55455 (E-mail: shumw001@umn.edu).

J Thorac Cardiovasc Surg 2017;153:e17-8 $0022-5223 / \$ 36.00$

Copyright (c) 2016 by The American Association for Thoracic Surgery http://dx.doi.org/10.1016/j.jtcvs.2016.09.069
}

Refractory air leaks after lung transplantation are a rare and challenging scenario. Endobronchial valves (EBVs) are effective in the management of refractory air leaks. ${ }^{1}$ We report a case of refractory post-transplant air leak in a patient with connective tissue disorders who required bilateral donor apical blebectomy treated successfully with EBV.

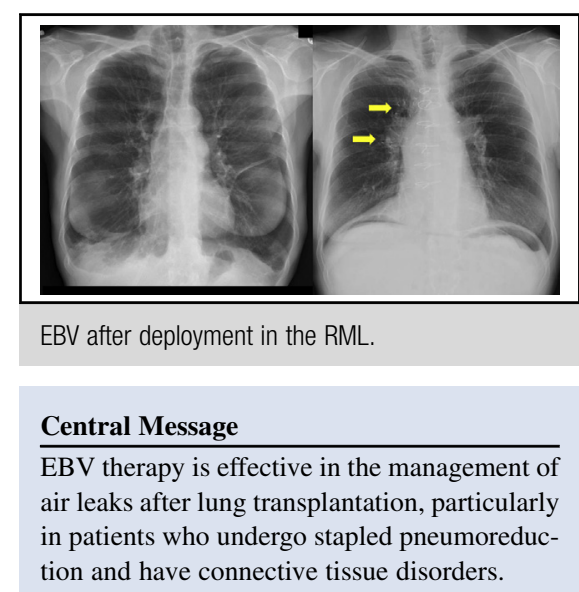

See Editorial Commentary page e19.

\section{CASE REPORT}

A 54-year-old woman with Ehlers-Danlos syndrome with dyspnea at rest for 7 years before transplant was diagnosed with alpha-1-antitrypsin deficiency. She experienced disease progression (lung allocation score, 33.566; predicted total lung capacity, $4.96 \mathrm{~L}$ ) and underwent bilateral lung transplantation. ${ }^{2}$ The donor was a 58-year-old man (predicted total lung capacity, 7.54 L) who had a severe fall. Although donor chest computed tomography was suggestive of small apical blebs, the terminal $\mathrm{PaO}_{2}: \mathrm{FiO}_{2}$ ratio was excellent and the lungs were accepted. The blebs were resected using standard white staple loads before implantation. No other abnormalities were identified. There were no intraoperative complications. Her immunosuppression regimen consisted of tacrolimus, mycophenolate mofetil, and prednisone (tapered per institutional protocol).

The patient was extubated on postoperative day (POD) 1 after normal flexible bronchoscopy. Bilateral air leaks and pneumothoraces developed on POD 4, which expanded with reduction of chest tube suction. These were attributed to allograft staple lines and observed. Repeat bronchoscopy on POD 10 was normal. Pleural apposition was present on the left side, but the right lung did not inflate fully despite maximum chest tube suction. Doxycycline pleurodesis was performed successfully on the left side on POD 28, although it was poorly tolerated. The patient underwent urgent cholecystectomy during the intervening period for a spontaneous hemocholecyst, delaying intervention on the leaks.
Flexible bronchoscopy was repeated on POD 33. Both bronchial anastomoses remained intact. The origin of the right upper lobe (RUL) bronchus was close to the anastomosis, and balloon isolation of this lobe was aborted because of the risk of anastomotic disruption. We assumed there was a leak from the RUL, so 3 EBVs (Spiration, Inc, Redmond, Wash) were deployed into the segmental bronchi of the RUL ( $7 \mathrm{~mm}$ anterior, $6 \mathrm{~mm}$ apical, and $7 \mathrm{~mm}$ posterior), which decreased the leak. All but 1 right chest tube, which remained to suction, was removed after the procedure. On POD 45, after failing chest tube weaning trials, sequential balloon isolation of the right segmental bronchi led to near-complete cessation of the leak with isolation of the right middle lobe (RML) bronchus, indicating the presence of transfissural ventilation supplying the RUL leak. Two 7-mm EBVs were placed in the RML bronchus. A blood patch was performed (instead of doxycycline per patient request) concurrently by instilling $100 \mathrm{~mL}$ of autologous blood into the right $32 \mathrm{~F}$ chest tube, which was clamped for 1 hour. The patient was repositioned frequently during this time. A simultaneous therapeutic pneumoperitoneum was performed to obliterate residual pleural space caused by lobar collapse due to EBV placement.

A small but expanded right pneumothorax was detected with a water seal on POD 49. The RML valves were repositioned, eliminating the transfissural air supply to the RUL and stopping the air leak (Figure 1). The leak recurred the next day and, because right-sided pleural apposition was 


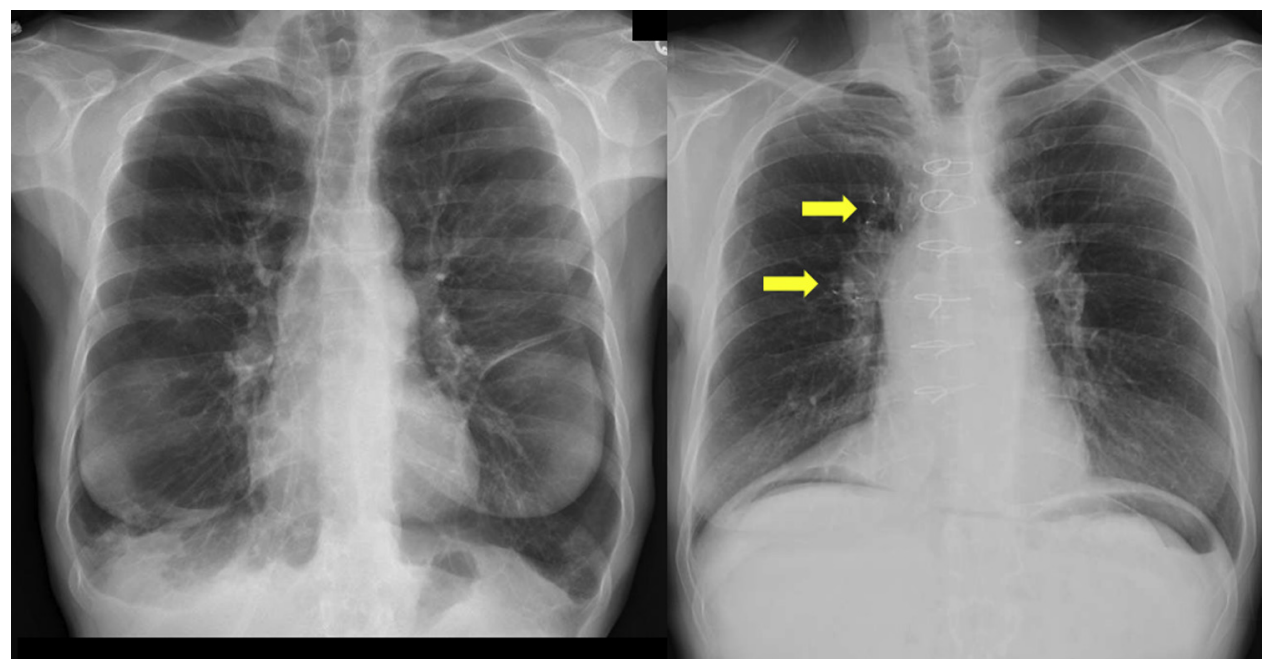

FIGURE 1. Chest radiograph before transplant (left) and after discharge (right). Note the presence of EBVs in the proximal airways of the RUL and RML (arrows), along with the therapeutic pneumoperitoneum.

improved, was treated successfully with doxycycline pleurodesis 2 days later. The right chest tube was removed, and the patient was discharged with good functional status and without supplemental oxygen shortly thereafter. The EBVs were removed 7 weeks postdischarge. She is doing well 1 year later.

\section{DISCUSSION}

EBVs are effective in the management of refractory air leaks. In our experience with a heterogeneous group of 19 medical and surgical patients treated with EBV, all leaks resolved and chest tubes were removed in a median of 3 days, although the number of valves, time to chest tube removal, and duration of therapy can vary. ${ }^{1}$

Stapled pneumoreduction at transplant allows the use of size-mismatched allografts but may cause transient air leaks from staple lines. It was required in this case because of apical blebs. Reinforced staple loads were not used; this likely contributed to the air leak. Despite a healthy donor, simultaneous Ehlers-Danlos syndrome, alpha-1-antitrypsin deficiency, and corticosteroid therapy conferred a greater risk of impaired staple line healing via leukocyte dysfunction and impaired collagen production. ${ }^{4,5}$ The most serious cause of refractory air leak after lung transplant is bronchial anastomotic dehiscence. Absent this, management is generally supportive. To our knowledge, this is the first report of the use of EBVs for the management of prolonged air leak after lung transplantation.

\section{CONCLUSIONS}

Prolonged air leak after lung transplantation poses a challenging clinical problem. Bronchial anastomotic dehiscence must be ruled out. Deployment of EBVs for such leaks may be beneficial in patients with connective tissue disorders.

\section{References}

1. Podgaetz E, Andrade RS, Zamora F, Gibson H, Dincer HE. Endobronchial treatment of bronchopleural fistulas by using intrabronchial valve system: a case series. Semin Thorac Cardiovasc Surg. 2015;27:218-22.

2. Ouwens JP, van der Mark TW, van der Bij W, Geertsma A, de Boer WJ, Koëter GH. Size matching in lung transplantation using predicted total lung capacity. Eur Respir J. 2002;20:1419-22.

3. Podgaetz E, Berger J, Small J, Garza R, Andrade R. Therapeutic pneumoperitoneum: relevant or obsolete in 2015? Thorac Cardiovasc Surg. January 12, 2016 [Epub ahead of print].

4. Meyer KC, Nunley DR, Dauber JH, Iacono AT, Keenan RJ, Cornwell RD, et al. Neutrophils, unopposed neutrophil elastase, and alpha1-antiprotease defenses following human lung transplantation. Am J Respir Crit Care Med. 2001;164: 97-102.

5. Kumar P, Sethi N, Friji MT, Poornima S. Wound healing and skin grafting in Ehlers-Danlos syndrome. Plast Reconstr Surg. 2010;126:214e-5e. 